\title{
Effect of Different Aluminium Powder Content on the Behaviour of Aerated Concrete: Experimental and Finite Element Validation
}

\author{
Rana Shabbar, Paul Nedwell, Mohammed Al-Taee, and Zhangjian Wu
}

\begin{abstract}
Aerated concrete is produced by introducing gas into a concrete which has a low tensile strength. The aim of the current study is to investigate the behaviour of aerated concrete with different Al content under monotonic loads. A finite element (FE) model to produce a more sophisticated explanation of the AC behaviour in compression, is constructed. The results showed that an increase in Al content caused a decrease in the compressive strength, modulus of elasticity and density of aerated concrete. FE outputs hold a close agreement with the experimental values which can be confidently used instead of further potential experimental work.
\end{abstract}

Index Terms-Aerated concrete, aluminium powder, concrete behaviour and finite element.

\section{INTRODUCTION}

Aerated concrete (AC) is produced by introducing gas bubbles into conventional concrete which produces a material of lower density. It is used not only as an insulating material for sound and heat, but also as a fire-resistant material. Light weight $\mathrm{AC}$ can be used to decrease the dead load, reduce the inertia effect during earthquakes and minimize the sections of the building members. Thus, the structural foundations become less demanding and the building cost is decreased [1], [2]. However, this type of concrete has lower mechanical properties and more cement may be required for the same strength as a normal concrete [3]. Typical lightweight concrete has densities from 1000 to $2000 \mathrm{~kg} / \mathrm{m}^{3}$ and compressive strengths from 1 to $100 \mathrm{~N} / \mathrm{mm}^{2}$ [4]. Many factors could influence these properties. Guglielmi et al. [5] studied the effect of aluminium powder $(0.2 \%$ $0.8 \%$ ) on the compressive strength of autoclaved clayey cellular concrete. It was noted that the compressive strength decreased slightly down $0.4 \%$ and then increased as the porosity decreased. It is found that with a high amount of aluminium powder, part of the hydrogen gas was not effective in producing pores when the reaction between hydroxides and aluminium took place. Raj and John [6] studied the effect of different aluminium powder percentages $(0.1,0.2,0.5,1,2$ and $5 \%)$ on the compressive strength of AC blocks. Their results showed that the compressive strength

Manuscript received December 19, 2016; revised April 5, 2017.

The authors are with School of Mechanical, Aerospace and Civil Engineering, University of Manchester, M13 9PL, UK, and Rana Shabbar is also with School of Engineering, University of Kufa, Najaf, Iraq (e-mail: author@nrim.go.jp). increased by increasing aluminium powder. However, addition of more than $5 \%$ aluminium powder caused the compressive strength and density to decrease drastically. Chaudhari and Chakrabarti [7] used finite element software ABAQUS to simulate and model a conventional concrete cube. The results showed that the material modelling of concrete by using concrete damage palsticity is matched with those obtained by experimental work in stresses. Ferretti et al. [8] studied crack development in autoclaved aerated concrete (AAC) walls under static loads. Three point bending tests on AAC beams under load control confirmed that the proposed model predicted the peak load correctly. Since the cost of experimental works is generally expensive for the large size structural members, the current study aims to investigate the effect of aluminium powder on the strength of AC structural members by laboratory tests and numerical modelling. A feasibility study of using further $\mathrm{FE}$ analysis for the modelling of cylinder AC samples with varying aluminium content, in comparison with real test results, was carried out to decrease the materials and time requirement for any further experimental tests.

\section{EXPERIMENTAL DETAILS}

\section{A. Materials and Mix Preparation}

AC composed of one part of CEM I/52.5N with two parts of Leighton Buzzard sand together with Al. The mix proportions of varying AC are shown in Table I. First, cement and sand were mixed together. Then $\mathrm{Al}$ powder was added and mixed for another $30 \mathrm{sec}$. Finally, water with the SP were added and mixed for $2 \mathrm{~min}$.

TABLE I: Mix PROPORTIONS OF THE AERATED CONCRETE WITH DIFFERENT ALUMINIUM POWDER CONTENTS

\begin{tabular}{lccccc}
\hline Material & \multicolumn{5}{c}{$\mathbf{k g} / \mathbf{m}^{\mathbf{3}}$} \\
& Mix 1 & Mix 2 & Mix 3 & Mix 4 & Mix 5 \\
\hline Cement & 350 & 350 & 350 & 350 & 350 \\
Sand & 700 & 700 & 700 & 700 & 700 \\
Water & 175 & 175 & 175 & 175 & 175 \\
Aluminium powder & 0 & 0.875 & 1.75 & 2.63 & 3.5 \\
Superplasticizer & 4.2 & 4.2 & 4.2 & 4.2 & 4.2 \\
\hline
\end{tabular}

\section{B. Specimens and Testing}

$100 \mathrm{~mm}$ cubes were used for compression test. The compressive strength of the AC was determined according to the BS 12390-3 [9]. Flexural strength was measured by using prisms with dimensions $100 \mathrm{~mm}$ cross section and $500 \mathrm{~mm}$ 
length according to the BS EN 12390-5 [10]. Cylinders with diameter $100 \mathrm{~mm}$ and length $200 \mathrm{~mm}$ were used for determined modulus of elasticity $\left(\mathrm{E}_{\mathrm{s}}\right)$ according to BS EN 12390-13 [11]. The dry density of the AC was measured according to the BS EN 992 [12].

\section{Finite ELEMENT VALIDATION}

Finite element analyses were conducted to model the compressive strength and tensile capacity of aerated concrete with different aluminium powder content. ABAQUS software version 6.14 was employed to simulate the aerated concrete failure model [13]. Two steel plates with the square cross section $150 \mathrm{~mm}$ and $30 \mathrm{~mm}$ thickness were placed on the top and bottom of the cylinder to ensure the uniform distribution of the axial applied load as shown in Fig. 1. A friction coefficient 0.57 between the steel plate and the samples was [14] realistically defined to provide the same situation as the experimental setup. Solid element type has been used to simulate the aerated concrete specimen; Concrete damage plasticity (CDP) model was used to model the behaviour of the aerated concrete with parameters, by trial and error, as shown in Table II. The mesh size of the steel plate was $10 \mathrm{~mm}$ whereas for the specimen was $5 \mathrm{~mm}$ as shown in Fig. 2.

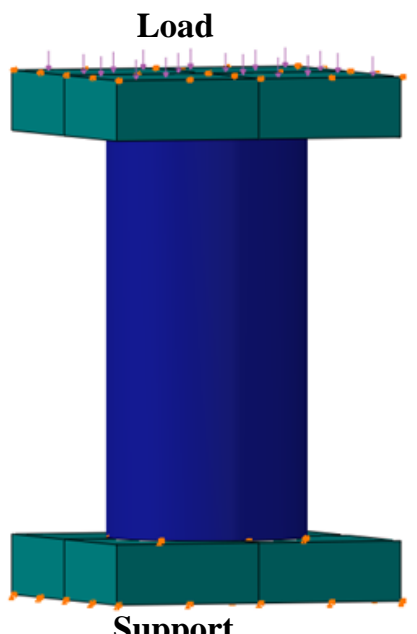

Support

Fig. 1. Model boundary conditions.

TABLE II: THE CDP PARAMETERS

\begin{tabular}{ccccc}
\hline DILATION ANGLE & THE ECCENTRICITY & $\mathbf{F}_{\mathrm{B}} / \mathbf{F}_{\mathbf{O}}$ STRESS RATIO & YIELD SURFACE (K) & VISCOSITY \\
\hline $40^{\circ}$ & 0.1 & 1.16 & $2 / 3$ \\
\hline
\end{tabular}

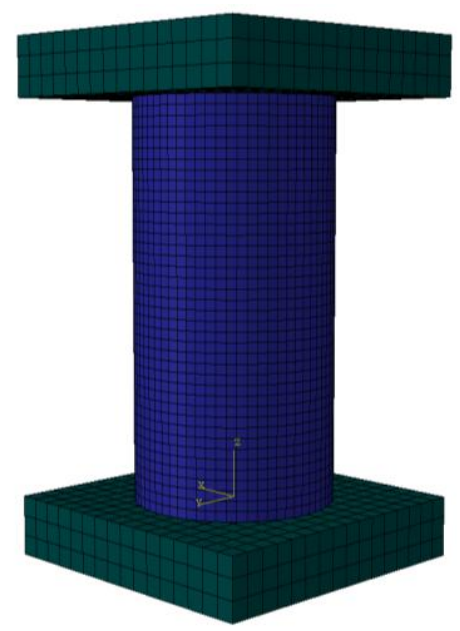

Fig. 2. Mesh size of a cylinder specimen and the steel plates.

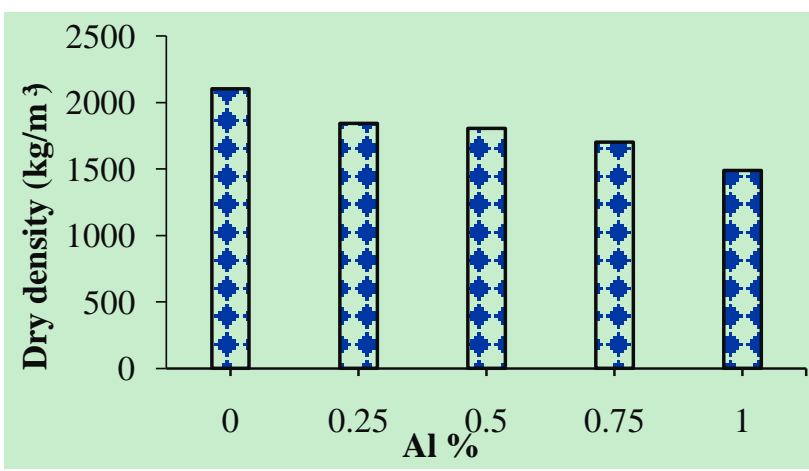

Fig. 3. Dry density of aerated concrete with varying al content.

\section{RESUlTS AND DISCUSSION}

\section{Experimental and FE Results}

The dry density of AC samples is a function of $\mathrm{Al}$ powder content as shown in Fig. 3. The result revealed that the dry density varied as expected for the different Al contents. It decreased as the foaming agent percentage increased because of the higher number of pores created. The density decreased from $2102 \mathrm{~kg} / \mathrm{m}^{3}$ for the AC with $0 \% \mathrm{Al}$ to $1841 \mathrm{~kg} / \mathrm{m}^{3}$ with $0.25 \% \mathrm{Al}$ powder. Then it decreased gradually with the increasing $\mathrm{Al}$ content. The lowest density was obtained with $1 \% \mathrm{Al}$ which was $1489 \mathrm{~kg} / \mathrm{m}^{3}$.

The 28 day's compressive strength results are presented in Fig. 4. It is observed that the compressive strength decreases with increasing of $\mathrm{Al}$ powder content. The lowest compressive strength was $19 \mathrm{~N} / \mathrm{mm}^{2}$ with $1 \% \mathrm{Al}$ due to largest amount of voids and lowest rate of calcium silicate hydrate (C-S-H) gel [5] . Thus, it did not contribute sufficiently to the compressive strength. The highest strength was for $0 \% \mathrm{Al}$ at $53 \mathrm{~N} / \mathrm{mm}^{2}$ which then decreased significantly on introduction of $0.25 \% \mathrm{Al}$ to $32 \mathrm{~N} / \mathrm{mm}^{2}$ and then decreased slightly as the $\mathrm{Al}$ increased with $26 \mathrm{~N} / \mathrm{mm}^{2}$ for $0.5 \%$ and $23 \mathrm{~N} / \mathrm{mm}^{2}$ for $0.75 \% \mathrm{Al}$.

The variations of the flexural strength of $\mathrm{AC}$ is presented in Fig. 4 which shows that it decreases when the $\mathrm{Al}$ content increases. The lowest flexural strength was $3.3 \mathrm{MPa}$ with $1 \%$ Al. The highest strength was for $0 \% \mathrm{Al}$ at $5.5 \mathrm{MPa}$ which then decreased slightly on introduction of $0.25 \% \mathrm{Al}$ to 4.6 $\mathrm{MPa}, 4.2 \mathrm{MPa}$ for $0.5 \%$ and $3.7 \mathrm{MPa}$ for $0.75 \% \mathrm{Al}$. Similar results were obtained by Eden et al [15] and Prakash et al [16], when the flexural strength increased due to an increase in density because low content of $\mathrm{Al}$.

Modulus of elasticity $\left(E_{s}\right)$ is mainly effected by the nature of the aggregates and cement paste. Additional effects are provided by the bond and arrangement between the particles [17]. Fig 5 presents the modulus of elasticity of AC with different $\mathrm{Al}$ content. In comparison to $0 \% \mathrm{Al}, \mathrm{AC}$ specimens 
have less stiffness due to the presence of the $\mathrm{Al}$, which caused larger and more pores to be formed and reducing strength. $\mathrm{AC}$ which was obtained from high $\mathrm{Al}$ powder content caused a greater loss in the $\mathrm{E}_{\mathrm{s}}$ than that with lower content. The lowest $\mathrm{E}_{\mathrm{s}}$ was $7.8 \mathrm{GPa}$ for $\mathrm{AC}$ with $1 \% \mathrm{Al}$. The highest $\mathrm{E}_{\mathrm{s}}$ was for $0 \% \mathrm{Al}$ at $23 \mathrm{GPa}$ which then decreased significantly on introduction of $0.25 \% \mathrm{Al}$ to $18.9 \mathrm{GPa}, 14.1 \mathrm{GPa}$ for $0.5 \%$ and $9.7 \mathrm{GPa}$ for $0.75 \% \mathrm{Al}$.

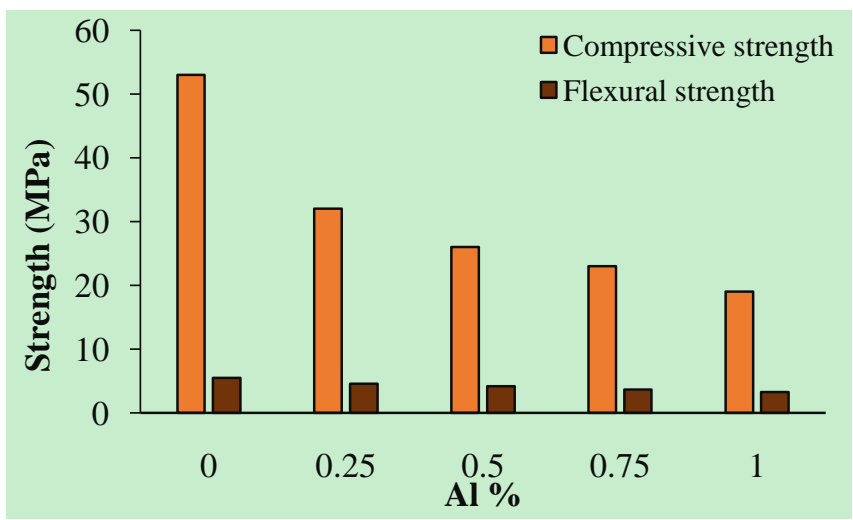

Fig. 4. Compressive and flexural strength of aerated concrete with varying al content.

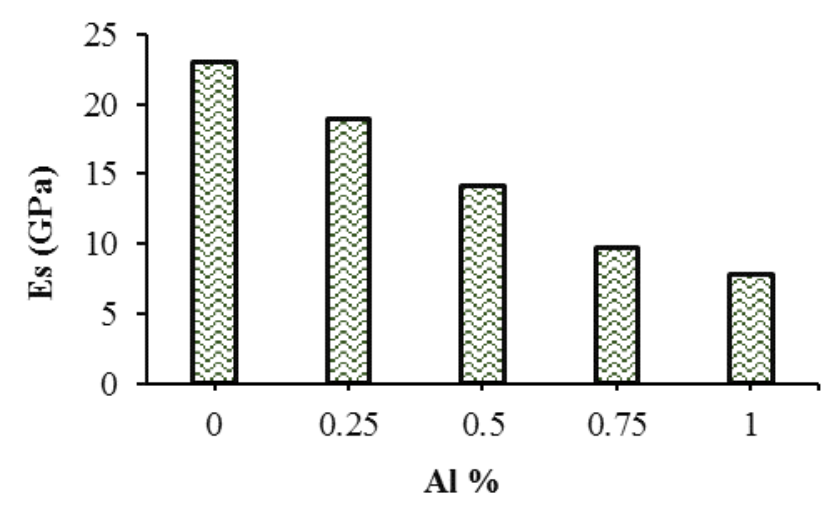

Fig. 5. Modulus of elasticityof aerated concrete with varying al content.

The initial linear portion of stress-strain in compression for $\mathrm{AC}$ with highest strength was steeper than that with lowest strength. This could due to its highest modulus of elasticity as shown in Fig. 6. In the non-linear ascending portion of the stress-strain curve, the $\mathrm{AC}$ with highest strength exhibited a stiffer non-linear curve. However, for AC with lowest strength showed a highest horizontal bend towards the peak stress. This can be referred to a lowest micro cracking in the $\mathrm{AC}$ with highest strength. The strain corresponding to the peak compressive strength is consider as one of the main parameters in the analytical modelling of the stress-strain relationship. The FE model was used to simulate the cylinder shown in Fig. 1. The stress-strain curves for AC specimens with different $\mathrm{Al}$ content for experimental and $\mathrm{FE}$ result are shown in Fig. 6.

It was observed that the stress-strain curve of the FEM and that from the experimental test are very close in the elastic region. However, in the plastic region, where the $\mathrm{AC}$ specimen starts giving plastic deformation, the stiffness decreases due to the formation of cracks. In addition, the experimental results have higher strain values when compared with FE. The data also showed fair agreement between FE and experimental test results and the percentage of the error between them ranged between $1.4 \%$ and $7.8 \%$. This gives confidence in the model to provide realistic results which may then be used instead of experimental work to decrease the materials required and time taken.

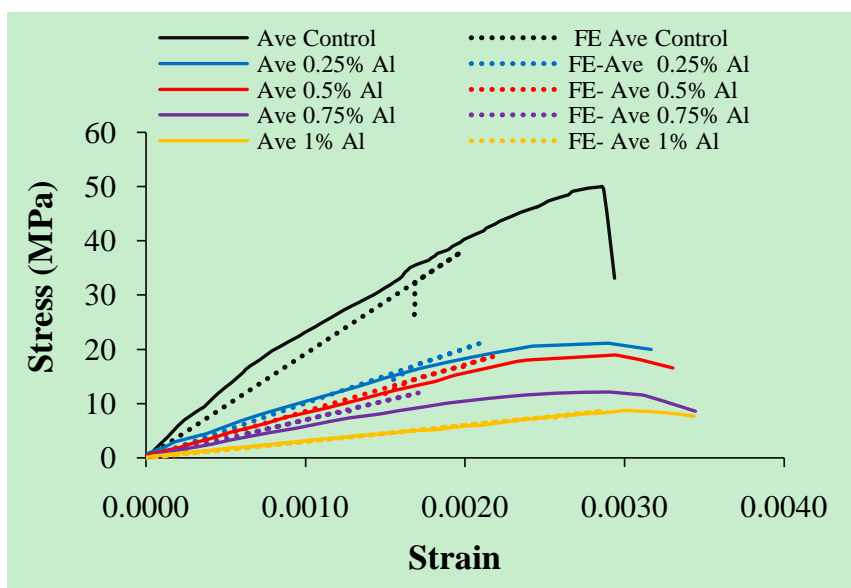

Fig. 6. Stress-strain of ac specimens with different al powder content and FE validation.

\section{CONCLUSIONS}

When the Al powder content increased, the dry density decreased gradually. The compressive, flexural strength and modulus of elasticity of the AC specimens declined according to the increase of the content of the Al.

The results showed that FEM can be used to analyse the behaviour of aerated concrete elements confidently. Such analytical modelling can be further used to analyse other concrete structures where the stress-strain behaviour is critical. FE could be used instead of experimental work to decrease the materials required and time taken.

\section{ACKNOWLEDGMENT}

The authors are grateful for financial support of the Iraqi ministry of high education and scientific research, technician support of Mr. John Mason in the school of MACE, University of Manchester.

\section{REFERENCES}

[1] D. H. Lim and B. H. Oh, "Experimental and theoretical investigation on the shear of steel fibre reinforced concrete beams," Engineering Structures, vol. 21, no. 10, pp. 937-944, 1999.

[2] O. A. Düzgün, R. Gül, and A. C. Aydin, "Effect of steel fibers on the mechanical properties of natural lightweight aggregate concrete," Materials Letters, vol. 59, pp. 27, pp. 3357-3363, 2005.

[3] A. M. Neville and J. J. Brooks, Concrete Technology. 2nd ed, Harlow: Longman Scientific \& Technical, 2010.

[4] A. M. Neville, Concrete Technology, Harlow: Longman Scientific \& Technical, 1987.

[5] P.O. Guglielmi et al., "Porosity and mechanical strength of an autoclaved clayey cellular concrete," Advances in Civil Engineering, 2010.

[6] I. S. Raj and E. John, "A study on the properties of air-entrained concrete for masonry blocks," International Journal of Scientific Engineering and Technology, vol. 3, no. 11, pp. 1367-1370, 2014.

[7] S. V. Chaudhari and M. A. Chakrabarti, "Modeling of concrete for nonlinear analysis Using Finite Element Code ABAQUS," International Journal of Computer Applications, vol. 44, no. 7, pp. 14-18, 2012.

[8] D. Ferretti, E. Michelini, and G. Rosati, "Cracking in autoclaved aerated concrete: Experimental investigation and XFEM modeling," Cement and Concrete Research, 2015.

[9] BS EN 12390-3, Testing Hardened Concrete. Compressive Strength of Test Specimens, 2009. 
[10] BS EN 12390-5, Testing Hardened Concrete. Flexural Strength of Test Specimens, 2009.

[11] BS EN 12390-13, Testing Hardened Concrete, Part 13: Determination of Secant Modulus of Elasticity in Compression, 2013.

[12] BS EN 992, Determination of the Dry Density of Lightweight Aggregate Concrete with Open Structure, 1996.

[13] Dassault Systèmes Company, ABAQUS/CAE User's Guide, Dassault Systèmes Simulia Corp: USA, 2014.

[14] B. Rabbat and H. Russell, "Friction coefficient of steel on concrete or grout," Journal of Structural Engineering, vol. 111, no. 3, pp. 505-515, 1985.

[15] N. B. Eden et al., "Autoclaved aerated concrete from slate waste Part 1: Some property/density relationships," International Journal of Cement Composites and Lightweight Concrete, vol. 2, no. 2, pp. 95-100, 1980

[16] T. M. Prakash, B. G. N. kumar, and Karisiddappa, "Strength and elastic properties of aerated concrete block masonry," International Journal of Structural and Civil Engineering Research, vol. 2, no. 1, 2013.

[17] R.V. Silva, J. de Brito, and R. K. Dhir, "Establishing a relationship between modulus of elasticity and compressive strength of recycled aggregate concrete," Journal of Cleaner Production, vol. 112, Part 4 pp. 2171-2186, 2016 .

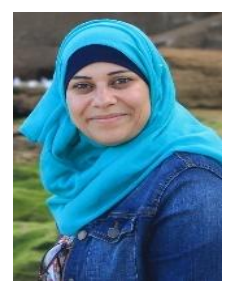

Rana Shbbar was born in Baghdad, Iraq in 1977 Rana recived a B.Sc degee from the Dept. of civil Engineering at Uinv of Mustenseria, Baghdad, Iraq in 2001 and MSc degree from the Dept. of Housing, Building and Planning at Uinv of Sains Malaysia, Penang, Malaysia in 2010. She is currently studying a $\mathrm{PhD}$ at MACE school, Univ of Manchester, UK.

She had worked as a senior lecturer at Engineering School, Univ of Diyala, Iraq from 2004 to 2005. Then she worked as a lecturer at Engineering school, Univ of Kufa, Iraq from 2011 to 2013.

Rana Shabbar is a member of Iraqi Engineers syndicate since 2002 and also a member of the institution of the structural engineers since 2015.

Some of her publications are listed as following: 1). R. Shabbar, P. Nedwell, and Z. Wu, "Effect of aluminium powder grading on the properties of aerated concrete," in Proc. 36th Cement and Concrete Science Conference, UK: Cementitious Material Group, Institute of Materials Minerals and Mining, 2016a. 2). R. Shabbar, P. Nedwell, M. Wilson, and Z. $\mathrm{Wu}$, "Porosity and sorptivity of aerated concrete with different aluminium powder content," International Journal of Chemical, Environmental \& Biological Sciences (IJCEBS), vol. 4, pp. 39-42, $2016 \mathrm{c}$. 